\title{
Complex Transitions from Skilled Nursing Facility to Home: Patient and Caregiver Perspectives
}

\author{
Jennifer L. Carnahan, MD, MPH, MA ${ }^{7,2,3}{ }^{(D)}$, Lev Inger, $M P H^{4}$, Susan M. Rawl, RN, PhD ${ }^{5,6}$, \\ Tochukwu C. lloabuchi, MD ${ }^{3}$, Daniel O. Clark, PhD ${ }^{1,2,3}$, Christopher M. Callahan, MD ${ }^{2,3}$, \\ and Alexia M. Torke, MD, MS \\ 'Indiana University Center for Aging Research, Indianapolis, IN, USA; ${ }^{2}$ Regenstrief Institute, Inc., Indianapolis, IN, USA; ${ }^{3}$ nndiana University School of \\ Medicine, Indianapolis, IN, USA; ${ }^{4}$ Parkview Research Center, Fort Wayne, IN, USA; ${ }^{5}$ Indiana University School of Nursing, Indianapolis, IN, USA: \\ ${ }^{6}$ Indiana University Simon Comprehensive Cancer Center, Indianapolis, IN, USA; ${ }^{7}$ Daniel F Evans Center for Spiritual and Religious Values in \\ Healthcare, Indianapolis, IN, USA.
}

BACKGROUND: Patients who undergo the complex series of transitions from the hospital to a skilled nursing facility (SNF) back to home represent a unique patient population with multiple comorbidities and impaired functional abilities. The needs and outcomes of patients who are discharged from the hospital to SNF before returning home are understudied in care transitions scholarship.

OBJECTIVE: To study the patient and caregiver challenges and perspectives on transitions from the hospital to the SNF and back to home.

DESIGN: Between $48 \mathrm{~h}$ and 1 week after discharge from the SNF, semi-structured interviews were performed with a convenience sample of patients and caregivers in their homes. Within 1 to 2 weeks after the baseline interview, follow-up interviews were performed over the phone.

PARTICIPANTS: A total of 39 interviewees comprised older adults undergoing the series of transitions from hospital to skilled nursing facility to home and their informal caregivers.

MAIN MEASURES: A constructionist, grounded-theory approach was used to code the interviews, identify major themes and subthemes, and develop a theoretical model explaining the outcomes of the SNF to home transition.

KEY RESULTS: The mean age of the patients was 76.6 years and 64.8 years for the caregivers. Four major themes were identified: comforts of home, information needs, post-SNF care, and independence. Patients noted an extended time away from home and were motivated to return to and remain in the home. Information needs were variably met and affected post-SNF care, including medication management, appointments, and therapy gains and setbacks. Interviewees identified independent function at home as the most important outcome of the transition home.

CONCLUSIONS: Post-SNF in home support is needed rapidly after discharge from the SNF to prevent adverse outcomes. In-home support needs to be highly individualized based on a patient's and caregiver's unique situation and needs.

Supplementary Information The online version contains supplementary material available at https://doiorg/10.1007/s11606-020-06332-w.

Received April 28, 2020

Accepted October 18, 2020

Published online November 2, 2020
KEY WORDS: care transitions; skilled nursing facility; home health; geriatrics.

J Gen Intern Med 36(5):1189-96

DOI: $10.1007 / \mathrm{s} 11606-020-06332-\mathrm{w}$

๑) Society of General Internal Medicine 2020

\section{INTRODUCTION}

Over $20 \%$ of hospitalized Medicare beneficiaries are discharged to a skilled nursing facility (SNF) for posthospital rehabilitation. ${ }^{1}$ SNFs act as safety nets for hospital discharge, for some of the most medically complex and vulnerable patients. ${ }^{2}$ Most patients admitted to a SNF will eventually go home, resulting in a second transition. Care transitions are burdensome for patients and often impair quality of life. ${ }^{3,4}$ Compared to patients who go directly home from the hospital, patients discharged to SNFs have more comorbidities and are at a higher risk for adverse events and more care transitions, including hospital readmissions. Despite these important differences, studies of this population are rare. ${ }^{5,6}$ This may be because the medical needs and focus of their health care shifts between physical locations and providers as they transition from the hospital to the SNF to home, making it difficult to gather and combine data from these isolated silos.

Prior research on care transitions from hospital to home have contributed to improved patient outcomes. ${ }^{4,7-13} \mathrm{Al}$ though some of these studies have included patients transitioning to SNFs, they have not addressed the unique needs of the patients transitioning from SNF to home. ${ }^{12,13}$ Of the recently published studies testing interventions designed to ease the transition from SNF to home, two relied on enhanced preparation of SNF staff to discharge patients home ${ }^{14,15}$; one study reduced 30 -day hospital readmissions ${ }^{14}$ and another is ongoing. ${ }^{15}$ Given the paucity of data specific to the group that undergoes this complex series of care transitions, investigation of this group's experience and needs is imperative. Therefore, the purposes of this study were to (1) understand the challenges faced by patients who were recently discharged from a SNF and their caregivers, (2) explore 
factors that promoted a successful transition, and (3) incorporate these findings into a framework for future research.

\section{METHODS}

This was a qualitative interview study using a constructionist, grounded theory approach to analyze the data. The Indiana University Review Board approved this study.

\section{SETTING AND CONTEXT}

\section{Participant Recruitment}

From September 2016 through June 2017, prior to their discharge, home eligible patients were referred to the study by one of three SNFs in Indianapolis. Informal caregivers were also enrolled if the patient identified them as "the person helping you to take care of yourself at home."

A convenience sample of participants was recruited by enrolling them from one of three referral facilities, which differed in ownership (government, for profit, and nonprofit) and had a different Medicare star rating (between 2 and 5) and a number of certified beds ranging from 70 to greater than 130 . To be eligible for the study, patients were required to (1) receive treatment prior to SNF admission at one of 3 affiliated hospitals, (2) be 65 years of age or older, (3) be community dwelling prior to hospital admission (including independent home, apartment, or assisted living), and (4) have resided in the SNF for 106 days or less, a criterion used in prior research because of the time limit of the SNF Medicare benefit. ${ }^{16} \mathrm{~A}$ brief screen was used to identify cognitive ability of participants. ${ }^{17}$

\section{Data Collection}

Patients were interviewed together with their caregivers in the patient's home within 2 to 7 days after returning home from a SNF stay. ${ }^{18}$ Interviews were conducted using a semistructured guide (Appendix). ${ }^{19}$ The guide included 10 openended questions and prompts that proceeded chronologically from the decision to go to a SNF, to the first day at home from the SNF, and then to medical issues going forward from their care transition. Prompts under each of the ten questions were provided to encourage elaboration on each topic and inquire about issues identified in previous care transitions literature. $^{7,12,20}$

One to 2 weeks after the baseline interview, follow-up interviews were conducted by phone with patients and caregivers to elicit any additional insights they may have on the transition process. For most dyads, this phone interview was conducted with the patient and caregiver separately. A few dyads requested that their interviews occur together. All interviews were recorded and transcribed verbatim by a professional transcription service. The admitting hospital's electronic medical record was reviewed to obtain health services and comorbidity information. Demographic information was obtained from interviewees.

\section{Data Analysis}

A constructionist, grounded theory approach was used to code the interviews and identify major themes and subthemes. ${ }^{18,21,22}$ Data analysis was started after completion of six baseline and three follow-up interviews. Analyses continued iteratively as interviews were completed until data saturation was reached. For initial coding, the six baseline and three follow-up interviews were independently read and coded by all members of the team (JC, LI, AT, and a trained research staff member KM). The team then met to create a preliminary code book. ${ }^{18}$ Subsequent interviews were coded by the principal investigator (JC) and one other member of the research team (AT, LI, or KM) until all of the interviews were coded. Team members met periodically to refine coding and emerging themes, and used a constant comparative approach to discuss the relationships among the codes both within and across interviews. ${ }^{19}$ The team discussed how individual codes were organized into larger themes and subthemes, and how themes related to each other in terms of conditions for transition, the transition itself, and outcomes of the transition, a process known as axial coding. ${ }^{19}$ Disagreements were resolved by consensus. If consensus could not be reached, the principal investigator made the final decision. Codes were entered into NVivo software Version 12. Interview findings were triangulated with existing care transitions literature to develop an explanatory theoretical model. ${ }^{19,23}$ Trustworthiness of the themes and theoretical model were reached by having more than one interviewer; multiple, independent coders; triangulation with the literature; and continuing interviews until theme saturation was reached. ${ }^{24}$

\section{RESULTS}

Of 64 patients and 17 caregivers of patients approached, 24 (39\%) patients and $15(88 \%)$ caregivers consented to the study and were interviewed (Table 1). Ten patients did not have a caregiver to interview and one reported two caregivers. The mean age of the patients was 76.6 years and 64.8 years for the caregivers.

Four major themes and ten subthemes were identified (Table 2).

\section{Comforts of Home}

From a favorite recliner, to sorely missed pets, to preferred foods, comforts of home were of paramount importance to participants. One example from a patient-caregiver combined interview follows:

"Tell me about the first day that you came home then from the facility? 
Table 1 Patient and Caregiver Characteristics and Outcomes

\begin{tabular}{|c|c|}
\hline Patient demographics, $n=24$ & $\begin{array}{l}\text { Number (\% or [mean } \\
\text { (range)]) }\end{array}$ \\
\hline Gender (female) & $16(66.7)$ \\
\hline Race-African American & $4(16.7)$ \\
\hline Race-Caucasian & $20(83.3)$ \\
\hline Age [mean (range)] & $76.6(66-91)$ \\
\hline 6 -item screener [mean (range)]* & $5.38(0-6)$ \\
\hline Caregiver(s) interviewed & $15(58.3)$ \\
\hline $\begin{array}{l}\text { Hospital length of stay (LOS) [mean days } \\
\text { (range)] }\end{array}$ & $7.39(2-17)$ \\
\hline SNF LOS [mean days (range)] & $32.2(9-91)$ \\
\hline $\begin{array}{l}\text { Total time away from home [mean days } \\
\text { (range)] }\end{array}$ & $39.6(14-108)$ \\
\hline $\begin{array}{l}\text { ED visits in } 6 \text { months prior to current } \\
\text { episode }\end{array}$ & $9(37.5)$ \\
\hline $\begin{array}{l}\text { Hospital admissions in } 6 \text { months prior to } \\
\text { current episode }\end{array}$ & $5(20.8)$ \\
\hline \multicolumn{2}{|c|}{ Caregiver demographics (interviewed 15 caregivers for 14 patients) } \\
\hline Gender (female) & $12(80.0)$ \\
\hline Race-African American & $1(6.7)$ \\
\hline Race-Caucasian & $14(93.3)$ \\
\hline Age [mean (range)] & $64.8(33-90)$ \\
\hline \multicolumn{2}{|l|}{ Outcomes } \\
\hline Discharge to assisted living & $4(16.7)$ \\
\hline Home health assistance at home & $18(75.0)$ \\
\hline Follow-up scheduled with PCP & $15(62.5)$ \\
\hline $\begin{array}{l}\text { Follow-up scheduled with multiple } \\
\text { providers }\end{array}$ & $15(62.5)$ \\
\hline Post-SNF discharge 30-day ED visit & $7(29.1)$ \\
\hline $\begin{array}{l}\text { Post-SNF discharge 30-day hospital } \\
\text { readmission }\end{array}$ & $6(25.0)$ \\
\hline $\begin{array}{l}\text { readmission } \\
30 \text {-day readmission among people with } \\
\text { caregivers }\end{array}$ & $2(8.3)$ \\
\hline $\begin{array}{l}\text { 30-day readmission among people } \\
\text { without caregivers }\end{array}$ & $4(16.7)$ \\
\hline Death within a year of SNF discharge & $2(8.3)$ \\
\hline
\end{tabular}

*The six-item screener was used to screen cognitive ability in participants and identify who needed a surrogate to consent for participation in research. It can also be used to describe the cognition of a subject and a score of 3 or less indicates probable cognitive impairment $^{17}$

\section{R: Bliss! \\ I: Bliss? \\ $\mathrm{R}:$ Oh yes!}

R2: You missed mom, that's what it was." (Baseline 06 , unless noted to be from a caregiver, all quotes are from patients with the number referencing the interview dyad identifier).

The duration away from home was salient to patients, who had a mean SNF stay of 32.2 days (Table 2, quotes 1.1a-1.1b). Though most patients were pleased to return home, 12 expressed a need to have stayed longer in the facility for rehabilitation. Some expressed ambivalence between wanting to be home and needing to stay in the SNF to acquire the skills required to be able to take care of oneself at home. For example, the same patient above who said returning home was blissful later remarked, "I was trying to get myself another, at least another week to ten days and they just come in on about Tuesday and said, you're going home Saturday...I did not get enough physical [therapy]" (baseline 06).

Despite not asking patients directly about nutrition, all mentioned it (Table 2, quotes $1.2 \mathrm{a}-1.2 \mathrm{c}$ ). The majority discussed their dislike of institutional food. Some patients and caregivers shared their struggle to adjust to new home dietary regimens. At least five patients not in assisted living also needed assistance securing food resources including help with groceries, food preparation, or a community meal delivery program.

Half of the patients mentioned missing the physical comforts of home such as a favorite easy chair or their own bed (Table 2, quotes 1.3a-1.3b). At least four patients and caregivers noted that adjustments had to be made for their return to home, such as rearranging furniture and installation of safety measures such as grab bars.

Social isolation and social interactions varied among patients, depending on their living situation and available community support (Table 2, quotes $1.4 \mathrm{a}-1.4 \mathrm{~d}$ ). Some missed the social activities of the SNF. Others were relieved that they no longer had to interact with the more frail and demented long-stay residents of the facility. Some remarked on their isolation at home, especially if their hospital illness had prompted more significant changes to their home environment such as moving to an assisted living facility. In addition to family and friends, the importance of returning home to cherished pets was significant for many (Table 2, quote $1.5 \mathrm{a}$ ).

\section{Information Needs}

While eight patients or patient-caregiver dyads felt the facilities prepared them well for discharge, at least five expressed uncertainty about their post-SNF health care (Table 2 , quotes 2.1a-2.2a). They described a plethora of papers related to their discharge home but found it difficult to locate relevant information in the materials. Patients further described that pertinent information was not available to their home care and primary care providers. For example, one patient noted that they had to recount the wound care orders for the home health nurse because the nurse had shown up the first day unaware of the wound, without the proper equipment, and had to improvise (baseline 10).

\section{Post-SNF Care}

All patients had some medical follow-up arranged within a week to a few months of SNF discharge, such as with home health or their primary care physician (Table 2, quote 3.1a). To manage numerous follow-up appointments, both patients and caregivers developed systems for keeping up with medical appointments such as online "family" calendars, paper desk calendars, or electronic word processing documents.

For medication management, patients and caregivers developed unique, personalized approaches. They noted different strategies for incorporating changes to their preillness medication regimen, some which resulted in taking the wrong medications until a home health worker could visit to perform medication reconciliation (Table 2; quotes $3.2 \mathrm{a}-3.2 \mathrm{~b})$. Of the 18 patients enrolled in home health 
Table 2 Skilled Nursing Facility to Home Transition: Themes and Subthemes

\section{Theme 1: Comforts of home}

Subtheme 1.1: Time away from home

Difficult duration away

1.1a "They had not seen me for a month and they were very glad to see me." (Baseline 10)

\section{Subtheme 1.2: Food}

Home food nostalgia

$1.2 \mathrm{a}$ "I fixed some jambalaya last night and he said he'd been eatin' bland food for so long...'cause he loves hot spicy food.” (Baseline 13)

\section{Subtheme 1.3: Physical space} Comfortable environment

1.3a "I was excited the day I came home and really looking forward to being there, and the first thing I did was plop down in my chair. It was very comfortable...But I was really, really excited and I was glad to be home." (Baseline 03)

\section{Subtheme 1.4: Social interactions}

Facility social interactions (+/-) $+$

$1.4 \mathrm{a}$ "I would like to be able to drive myself so I can get to $[\mathrm{SNF}]$ and check up on some of my friends that I made while I was there." (Follow-up 14)

\section{Medical diet}

$1.2 \mathrm{~b}$ "On top of that they did change how his diabetes was managed and I think having some nutritional guidance would've been helpful.... We're just guessing." (Baseline 21)

\section{$-$}

$1.4 \mathrm{~b}$ "The last few days I did not go down for supper because we had some different people at the table and between their hocking, and spitting, and carrying on, and food dribbling down their face... So I just took my little walk and I went back to my room and had a Boost." (Baseline 18)
Needs more time in SNF

$1.1 \mathrm{~b}$ "Well I was prepared to come home but... they wanted me to stay longer but could not do it. The insurance was running out..... I: So what areas did you feel like needed to be a little more strengthened before you could come home?

R: My legs." (Baseline 17)

Food insecurity

$1.2 \mathrm{c}$ "She just did all the paperwork; she got Meals on Wheels to come in for me." (Baseline 01)

\section{Environmental adjustments}

$1.3 \mathrm{~b}$ "We moved a cedar chest out of the way, put it in another room so that he could have more room in the bedroom to walk... I bought his walker. I bought diapers. I bought pads..." (Baseline 13)

\section{Home social interactions (+/-) $+$ $1.4 \mathrm{c}$ "The first day I came home it felt like, it felt like I had been gone from home forever, you know? And I was just returning home, and it really, really made me feel good to be around the rest of my family that I had been missing." (Baseline 23)}

.4d "I could not understand why my husband ... got so upset at me cause I could not do this and I could not do that...I think I'm going to have to do more adjusting than he is because I'm a worrywart and he just - he's not." (Baseline 01)

\subsection{Well-being and mood}

1.5 a "I was having a blue day [back at home]. I call it a blue day where I did not think I'd ever get to a point to where I could get my dog back and they reassured me that, you know, it's not been that long since I've had my support...on and they will continue to care for my dog. I miss him so much. I really do." (Follow-up 14)

Theme 2: Information needs

2.1 Transition plan uncertainties

2.1a "The only thing that I would like to add is, I wish they would have given a couple of more instructions about getting her in and out of the wheelchair and what she was doing up to that point... if you are a novice, you would not have a clue." (Follow-up 05-caregiver)

Theme 3: Post-SNF care

3.1 Medical care and appointments

3.1a "I have got to schedule with the primary and then I'm going to schedule on the knee...then his eyes and then...ears too." (Baseline 08)

\subsection{Medication management}

3.2a "...And she had 4 new medicines, 4,5 new medicines "cause they eliminated some. So it was like a giant jigsaw puzzle." (Baseline 18)

$3.2 \mathrm{~b}$ "I have not gotten my medications yet... when I did come home, I went back to taking the medications I was taking before I went, which is almost the same..." (Baseline 12)

\section{Theme 4: Independence}

\subsection{Increasing independence}

4.1a "R: I'm just helping her out until she can be more independent... physical therapy and OT are helping her adjust to her surroundings there... and this is an adjustment time for her because she is facing with this new possible diagnosis of Parkinson's...but I want her to be able to be independent as possible." (Follow-up 14 - caregiver)

\subsection{Paperwork overload}

2.2a "I: And, did they give you any written information or papers when you left the facility?

R: I got, yeah, but I ain’t ever looked through 'em yet.” (Baseline 13)

\subsection{Therapy gains and setbacks}

3.3a "I think I've missed the therapy... I've gotten kind of stiff and everything so I think if we could have started the therapy sooner it would have been better." (Follow-up 03)

\subsection{Need for assistance}

4.2a "On Mondays, I got my shower with a home health aide here and Tuesdays, a nurse came to wrap my legs, and I was doing the Unna boots at that time. Then they came and take the wrappings off on Wednesday night and on Thursday morning, I would get my shower again and then on Friday, they would come and put the Unna boots back on me and then I'd have that until Monday when I got my shower. I think I'm off Sunday night." (Baseline 02) care, only 11 reported additional assistance with medications. Patients also experienced a delay in starting home therapy. The delay between SNF discharge and home therapies had the potential for setbacks in the functional status of patients (Table 2, quote $3.3 \mathrm{a}$ ).

\section{Independence}

Patients experienced a juxtaposition of reduced independence in activities of daily living (ADL) in the SNF with the need to develop skills to enhance independence for resumption of life at home (Table 2, quotes 4.1a-4.2a). In the SNF, many ADLs 
were handled by the staff, while patients had few responsibilities. After transition home, patients resumed responsibility for more of their care, although the balance of roles varied among patient/caregiver dyads. Caregivers often had their own goals for patients' independence at home. Both patients and caregivers expressed frustration at lost or reduced independence upon returning home.

\section{THEORETICAL MODEL}

\section{Patient, Caregiver, and Clinician Health Management Roles}

We identified shifts in roles and responsibilities from the SNF to home (Fig. 1). Over time and depending on the health care setting, patients, caregivers, and health care professionals assume more or less of the responsibility for caregiving, which reflects the juxtaposition identified in the theme of independence. Patients in the SNF were highly dependent on staff. After the transition to home, the patient and caregiver take on greater responsibility. The pie charts in Figure 1 illustrate an example of the degree of help and independence a patient may need or have at different timepoints in their health trajectory and locations of care. This is paired with an explanatory model (Fig. 2) that depicts the antecedents, mediators, and outcomes important in the transition from SNF to home. Although the actual physical transition is brief, the experience is a pivotal concept in the model as a point of transformation before returning to the community. ${ }^{25}$

\section{Patient/Clinical Context}

Prior literature has identified several sociodemographic factors that affect care transitions including the transition from SNF to home. Non-white race, poverty, and social isolation have been linked to poor transition outcomes. ${ }^{4,5,26}$ In addition, patients and caregivers described concepts that were especially salient for patients who had transitioned from hospital to SNF to home. Time away from home was a minimum of 2-3 weeks, sometimes several months. This was forefront in at least half of the patients' minds and is an important difference between these patients and those discharged directly home from the hospital. The comforts of home that patients missed during their time away were what motivated and inspired them to work with therapists on achieving a level of independence in their functional ability that enabled them to safely return home. Additionally, social interaction and isolation and ability to obtain food, supplies, and medications were crucial to the experience of successful transition.

\section{Preparation for and Arrival at Home}

Despite efforts to prepare for discharge, there were many uncertainties that arose once patients were home. Information needs expressed by patients and caregivers about the transition plan were often unmet. Although patients received a lot of paperwork, most did not read it or find it useful, suggesting a need for improvement in the preparation of patients and caregivers for discharge. Discharge planning that is individually tailored to patient and caregiver needs may improve outcomes for patients transitioning from SNF to home.

Post-SNF care arose as a key component of a successful transition. First, patients and caregivers identified a gap between SNF discharge and resumption of physical and occupational therapy at home, a time when gains made in the SNF might be lost. Medical appointments after SNF discharge were complicated due to the many comorbidities and needs of the patients. Medication management was challenging and eight dyads voiced confusion about medications. This was compounded by the fact that medication regimens are changed both in during the hospital stay and in during the SNF stay. Patients varied in their ability to organize their medications and take them as prescribed.

A patient's ability to reintegrate themselves into their previous lives at home ensured a successful transition. This depended on how independent they were, how motivated they were to regain independence, and the availability of a caregiver. The patient or caregiver's ability to manage each of the important aspects of the transition based on knowledge, skills, and resources was essential to success. Additionally resources that enable function at home, transportation availability, and other social capital were fundamental to a successful transition

\section{Outcomes}

Patients described the importance of staying at home, providing patient-centered evidence for reduction of acute care utilization and nursing home placement as an important goal. One caregiver noted that the patient knew, "there's not many

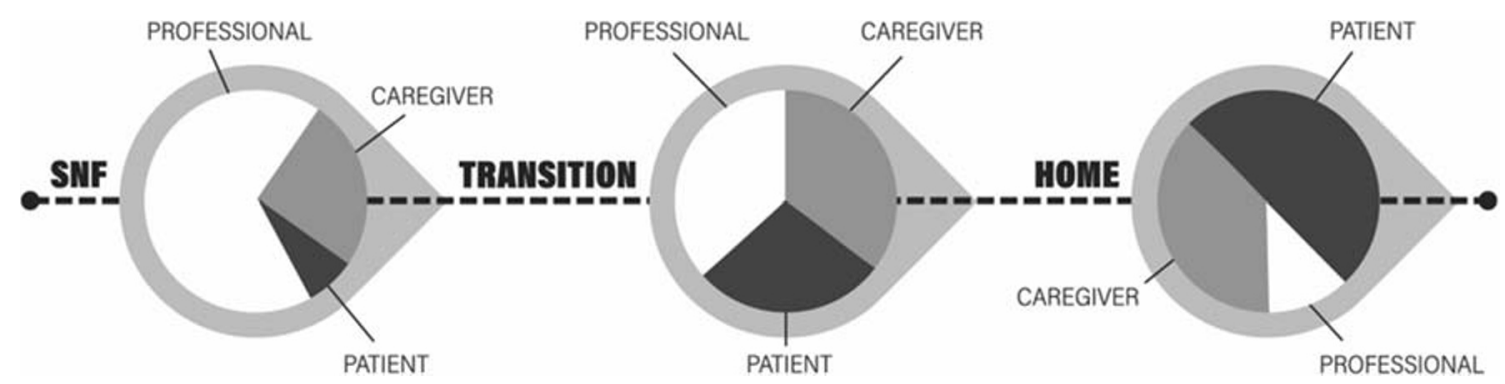

Figure 1 Example of shifting roles and responsibilities for patient's health and personal care. 


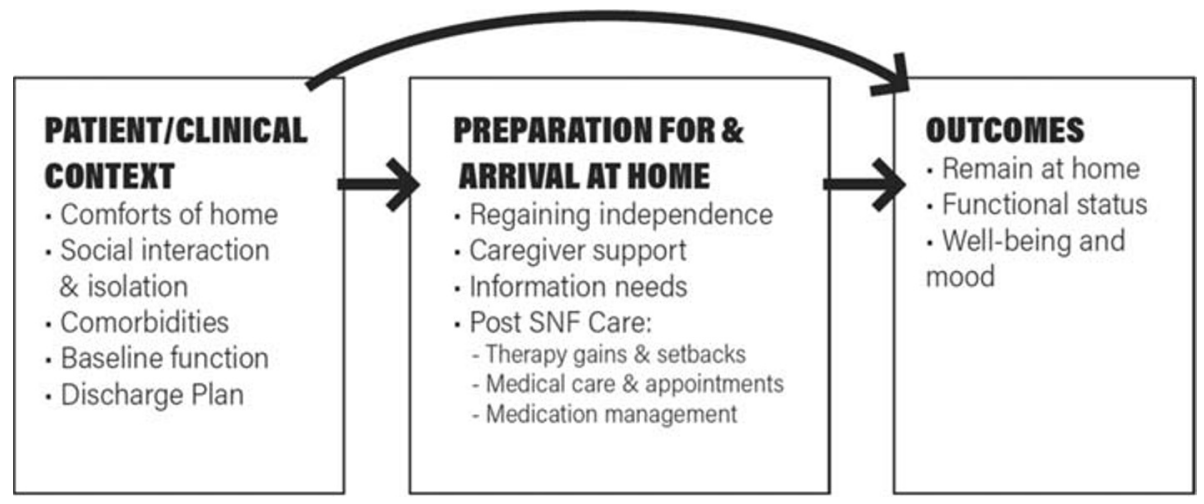

Figure 2 Model of skilled nursing facility to home context, transition, and outcomes.

options unless he wants to go back to the hospital or long term care," (baseline 07). Patients and caregivers also expressed concerns with decline in function and mood after returning home (quotes $1.5 \mathrm{a}$ and $3.3 \mathrm{a}$ ), both which could result in return to acute care.

\section{DISCUSSION}

This qualitative study of patients and caregivers recognized key themes essential to a successful transition that have been identified in prior literature, including (1) effective education/ preparation of patients and caregivers for discharge, (2) transfer of information to community providers, and (3) medication reconciliation. ${ }^{7,9,13}$ Our study found several additional factors that are highly salient in the SNF to home population. First, patients were discharged home after weeks or months away from home. Returning to the comforts of home and resumption of life at home was heightened in importance, although changes in function may have resulted in unexpected new challenges in the home environment.

Second, patient and caregiver accounts revealed that the transition home often leads to interruptions or disruptions of two important aspects of patient care, medication management, and rehabilitation. Medication support needs to be immediately available after patients return home and should be highly individualized based on a patient's cognitive status, health literacy, functional abilities, and medical comorbidities. Additionally, a gap in therapy can result in loss of functional gains made. Lower premorbid functional status combined with hospital-associated declines in function for this population meant that any gap at home in the resumption of physical, occupational, or speech therapy was especially problematic. $^{27,28}$ Our qualitative results confirm the findings of other studies that early home health has great potential to reduce readmissions after the SNF to home transition. ${ }^{29,30}$

Finally, transfer of information was incomplete in our study; however, other studies have shown that information transfer alone will not solve care transition difficulties. ${ }^{31,32}$ Thus, an appreciation of the specific needs of an individual patient coupled with an understanding of the common themes identified by this study would enhance the transition home from the SNF. Multi-modal approaches are necessary for interventions with complex older adult populations. ${ }^{33-35}$

An intervention to enhance care transitions should be delivered rapidly after the patient returns home and employ a multi-modal approach. Such interventions have great potential to support patients to remain at home and resume normal activities, and optimally participate in their personal and medical care. Although readmission penalties have been debated and criticized for creating unintended consequences, there is consensus that improvements in transitional care are needed. ${ }^{36-40}$ Preventing avoidable use of acute care services, emergency room visits, and hospital readmissions remains an important outcome for patients, caregivers, providers, and health systems.

\section{Limitations}

We enrolled patients and caregivers in one Midwestern metropolitan area which may limit generalizability to other regions. Some patients in the study received Medicaid benefits, which varies by state. As a result, some of the perceived needs and difficulties with the care transition may vary by state and by type of insurance. Thus, this study may need to be replicated in other settings, and the rich qualitative results need to be further explored with quantitative methods.

\section{CONCLUSION}

This study characterizes the most important factors in the transition from SNF to home and can guide development of interventions. Similar to previous care transitions programs such as the Care Transitions Intervention, medication management and scheduled follow-up appointments remain important. ${ }^{12,13}$ While prior transitions models have focused on the need for an improved, patient-centered medical record, patients and caregivers in this study describe needing more tailored information about medications, and ongoing rehabilitation and therapy. Further, the need for functional rehabilitation, eliminating gaps in professional support during the transition, and providing customized information about the 
transition are factors more prominent in the SNF to home transition that must be addressed in the immediate period following transition home. An intervention that addresses these barriers and is tailored to individual patient and caregiver needs has the potential to improve health outcomes for both patients and caregivers.

Acknowledgments: Kianna Montz, MA, assisted with early data collection and coding.

Corresponding Author: Jennifer L. Carnahan, MD, MPH, MA; Indiana University School of Medicine, Indianapolis, IN, USA (e-mail: jenncarn@iupui.edu).

Funding Dr. Carnahan reports support from Grant Numbers KL2TRO02530 (A Carroll, PI) and UL1TR002529 (A. Shekhar, PI) from the National Institutes of Health, National Center for Advancing Translational Sciences, Clinical and Translational Sciences Award, the National Institute On Aging of the National Institutes of Health under Award Number K23AG062797, and the Regenstrief Foundation. Dr. Torke was supported by a Midcareer Investigator Award in Patient Oriented Research (K24AG053794).

\section{Compliance with Ethical Standards:}

The Indiana University Review Board approved this study

Conflict of Interest: The authors declare that they do not have a conflict of interest.

Disclaimer: The content is solely the responsibility of the authors and does not necessarily represent the official views of the National Institutes of Health or of the Regenstrief Institute, Inc.

\section{REFERENCES}

1. Mor V, Intrator O, Feng Z, Grabowski DC. The revolving door of rehospitalization from skilled nursing facilities. Health Affairs (Project Hope). 2010;29(1):57-64.

2. Mor V. The Need to Realign Health System Processes for Patients Discharged From the Hospital-Getting Patients HomeThe Need to Realign Health System Processes for Patients Discharged From the HospitalEditorial. 2019.

3. Callahan CM, Arling G, Tu W, et al. Transitions in care for older adults with and without dementia. J Am Geriatr Soc. 2012;60(5):813-820.

4. Greysen SR, Hoi-Cheung D, Garcia V, et al. "Missing pieces"-functional, social, and environmental barriers to recovery for vulnerable older adults transitioning from hospital to home. J Am Geriatr Soc. 2014;62(8):15561561

5. Iloabuchi TC, Mi D, Tu W, Counsell SR. Risk factors for early hospital readmission in low-income elderly adults. J Am Geriatr Soc. 2014;62(3):489-494.

6. David S, Sheikh F, Mahajan D, Greenough W, Bellantoni M. Whom Do We Serve? Describing the target population for post-acute and long-term care, focusing on nursing facility, settings, in the era of population health 2016. http://www.paltc.org/amda-white-papers-and-resolution-position-statements/whom-do-we-serve-describing-target-population Accessed 18 April 2016

7. Naylor MD, Brooten D, Campbell R, et al. Comprehensive discharge planning and home follow-up of hospitalized elders: a randomized clinical trial. Jama. 1999;281(7):613-620.

8. Kripalani S, LeFevre F, Phillips CO, Williams MV, Basaviah P, Baker DW. Deficits in communication and information transfer between hospital-based and primary care physicians: implications for patient safety and continuity of care. Jama. 2007;297(8):831-841.

9. Jack BW, Chetty VK, Anthony D, et al. A reengineered hospita discharge program to decrease rehospitalization: a randomized trial. Ann Intern Med. 2009;150(3):178-187.
10. Kind AJ, Jensen L, Barczi S, et al. Low-cost transitional care with nurse managers making mostly phone contact with patients cut rehospitalization at a VA hospital. Health Affairs (Project Hope). 2012;31(12):26592668.

11. Hansen LO, Greenwald JL, Budnitz T, et al. Project BOOST: effectiveness of a multihospital effort to reduce rehospitalization. J Hosp Med. 2013;8(8):421-427.

12. Parry C, Coleman EA, Smith JD, Frank J, Kramer AM. The care transitions intervention: a patient-centered approach to ensuring effective transfers between sites of geriatric care. Home Health Care Serv Q. 2003;22(3): 1-17.

13. Coleman EA, Smith JD, Frank JC, Min SJ, Parry C, Kramer AM Preparing patients and caregivers to participate in care delivered across settings: the Care Transitions Intervention. J Am Geriatr Soc. 2004;52(11):1817-1825.

14. Berkowitz RE, Fang Z, Helfand BK, Jones RN, Schreiber R, PaascheOrlow MK. Project ReEngineered Discharge (RED) lowers hospital readmissions of patients discharged from a skilled nursing facility. J Am Med Dir Assoc. 2013;14(10):736-740.

15. Toles M, Colon-Emeric C, Naylor MD, Asafu-Adjei J, Hanson LC. Connect-Home: Transitional Care of Skilled Nursing Facility Patients and their Caregivers. J Am Geriatr Soc. 2017;65(10):2322-2328.

16. Toles M, Anderson RA, Massing M, et al. Restarting the cycle: incidence and predictors of first acute care use after nursing home discharge. J Am Geriatr Soc. 2014;62(1):79-85.

17. Callahan CM, Unverzagt FW, Hui SL, Perkins AJ, Hendrie HC. Six-item screener to identify cognitive impairment among potential subjects for clinical research. Med Care. 2002;40(9):771-781.

18. Giles TM, de Lacey S, Muir-Cochrane E. Coding, Constant Comparisons, and Core Categories: A Worked Example for Novice Constructivist Grounded Theorists. ANS Adv Nurs Sci. 2016;39(1):E29-44.

19. Charmaz K. Constructing grounded theory. In. 2nd ed. London;: Sage; 2014.

20. Coleman EA, Min SJ, Chomiak A, Kramer AM. Posthospital care transitions: patterns, complications, and risk identification. Health Serv Res. 2004;39(5):1449-1465.

21. JA H. The Coding Process and Its Challenges. In: Bryant A, Charmaz K, eds. The SAGE handbook of grounded theory. Los Angeles [i.e. Thousand Oaks, Calif.] :: SAGE Publications; 2010.

22. The SAGE handbook of grounded theory. In: Bryant A, Charmaz K, eds. Pbk. ed. ed. Los Angeles [i.e. Thousand Oaks, Calif.] :: SAGE Publications; 2010.

23. Borkan J. Immersion/Crystallization. In: Crabtree BF, Miller WL, eds. Doing Qualitative Research 2nd ed. Thousand Oaks: Sage Publications, Inc.; 1999.

24. Guba EG, Lincoln YS. Competing Paradigms in Qualitative Research. In Denzin NK, Lincoln YS, eds. Handbook of Qualitative Research. Sage Publications; 1994:105-117.

25. Turner V. The Ritual Process: Structure and Anti-Structure. Hawthorne, NY: Aldine de Gruyter; 1995.

26. Li Y, Cai X, Glance LG. Disparities in 30-Day Rehospitalization Rates Among Medicare Skilled Nursing Facility Residents by Race and Site of Care. Med Care. 2015;53(12): 1058-1065.

27. Boyd CM, Landefeld CS, Counsell SR, et al. Recovery of activities of daily living in older adults after hospitalization for acute medical illness. J Am Geriatr Soc. 2008;56(12):2171-2179.

28. Mudge AM, McRae P, Hubbard RE, et al. Hospital-Associated Complications of Older People: A Proposed Multicomponent Outcome for Acute Care. J Am Geriatr Soc. 2019;67(2):352-356.

29. Carnahan JL, Slaven JE, Callahan CM, Tu W, Torke AM. Transitions From Skilled Nursing Facility to Home: The Relationship of Early Outpatient Care to Hospital Readmission. J Am Med Dir Assoc. 2017;18(10):853-859.

30. Weerahandi $\mathbf{H}$, Bao $\mathbf{H}$, Herrin $\mathbf{J}$, et al. Home Health Care After Skilled Nursing Facility Discharge Following Heart Failure Hospitalization. J Am Geriatr Soc. 2020;68(1):96-102.

31. Donovan JL, Kanaan AO, Gurwitz JH, et al. A Pilot Health Information Technology-Based Effort to Increase the Quality of Transitions From Skilled Nursing Facility to Home: Compelling Evidence of High Rate of Adverse Outcomes. J Am Med Dir Assoc. 2016;17(4):312-317.

32. Karapinar-Çarkıt F, Borgsteede SD, Janssen MJA, et al. The effect of a pharmaceutical transitional care program on rehospitalisations in internal medicine patients: an interrupted-time-series study. BMC Health Serv Res. 2019;19(1):717. 
33. Ross DM, Ramirez B, Rotarius T, Liberman A. Health care transitions and the aging population: a framework for measuring the value of rapid rehabilitation. Health Care Manag (Frederick). 2011;30(2):96-117.

34. Messinger-Rapport BJ, Little MO, Morley JE, Gammack JK. Clinical Update on Nursing Home Medicine: 2016. J Am Med Dir Assoc. 2016;17(11):978-993.

35. Kapoor A, Field T, Handler S, et al. Adverse Events in Long-term Care Residents Transitioning From Hospital Back to Nursing Home. JAMA Intern Med. 2019;179(9):1254-1261.

36. Wadhera RK, Joynt Maddox KE, Wasfy JH, Haneuse S, Shen C, Yeh RW. Association of the hospital readmissions reduction program with mortality among medicare beneficiaries hospitalized for heart failure, acute myocardial infarction, and pneumonia. Jama. 2018;320(24):25422552.

37. Jha AK. Death, Readmissions, and Getting Policy RightDeath, Readmissions, and Getting Policy RightInvited Commentary. JAMA Netw Open. 2018;1(5):e182776.

38. Dharmarajan K, Wang Y, Lin Z, et al. Association of Changing Hospital Readmission Rates With Mortality Rates After Hospital Discharge. Jama. 2017;318(3):270-278.
39. Joynt Maddox KE, Reidhead M, Qi AC, Nerenz DR. Association of Stratification by Dual Enrollment Status With Financial Penalties in the Hospital Readmissions Reduction Program. JAMA Intern Med. 2019;179(6):769-776.

40. Naylor MD, Kurtzman ET, Grabowski DC, Harrington C, McClellan M, Reinhard SC. Unintended consequences of steps to cut readmissions and reform payment may threaten care of vulnerable older adults. Health Affairs (Project Hope). 2012;31(7):1623-1632.

Publisher's Note Springer Nature remains neutral with regard to jurisdictional claims in published maps and institutional affiliations. 